\title{
IDentification of patients in need of general and specialised PALLiative care (ID-PALLC): item generation, content and face validity of a new interprofessional screening instrument
}

\author{
Fabienne Teike Lüthi $i^{1,2^{*+}}$ (D), Mathieu Bernard ${ }^{2+}$ (D) Michel Beauverd ${ }^{2}$ (D) Claudia Gamondi ${ }^{2,3}$ (D),
} Anne-Sylvie Ramelet ${ }^{1+}$ (D) and Gian Domenico Borasio $^{2+}$ (D)

\begin{abstract}
Background: Early identification of patients requiring palliative care is a major public health concern. A growing number of instruments exist to help professionals to identify these patients, however, thus far, none have been thoroughly assessed for criterion validity. In addition, no currently available instruments differentiate between patients in need of general vs. specialised palliative care, and most are primarily intended for use by physicians. This study aims to develop and rigorously validate a new interprofessional instrument allowing identification of patients in need of general vs specialised palliative care.

Methods: The instrument development involved four steps: i) literature review to determine the concept to measure; ii) generation of a set of items; iii) review of the initial set of items by experts to establish the content validity; iv) administration of the items to a sample of the target population to establish face validity. We conducted a Delphi process with experts in palliative care to accomplish step 3 and sent a questionnaire to nurses and physicians non-specialised in palliative care to complete step 4. The study was conducted in the French and Italian-speaking regions of Switzerland. An interdisciplinary committee of clinical experts supervised all steps.

Results: The literature review confirmed the necessity of distinguishing between general and specialised palliative care needs and of adapting clinical recommendations to these different needs. Thirty-six nurses and physicians participated in the Delphi process and 28 were involved in the face validity assessment. The Delphi process resulted in two lists: a 7-item list to identify patients in need of general PC and an 8-item list to identify specialised PC needs. The content and face validity were deemed to be acceptable by both the expert and target populations.

(Continued on next page)
\end{abstract}

\footnotetext{
* Correspondence: Fabienne.Teike-luethi@chuv.ch

${ }^{\dagger}$ Fabienne Teike Lüthi and Mathieu Bernard are first authors contributed equally

${ }^{+}$Anne-Sylvie Ramelet and Gian Domenico Borasio are last authors contributed equally

'Institute of Higher Education and Research in Healthcare, University of Lausanne and Lausanne University Hospital, Lausanne, Switzerland

2Palliative and Supportive Care Service, Lausanne University Hospital and

University of Lausanne, Lausanne, Switzerland

Full list of author information is available at the end of the article
}

(c) The Author(s). 2020 Open Access This article is distributed under the terms of the Creative Commons Attribution 4.0 International License (http://creativecommons.org/licenses/by/4.0/) which permits unrestricted use, distribution, and reproduction in any medium, provided you give appropriate credit to the original author(s) and the source, provide a link to the Creative Commons license, and indicate if changes were made. The Creative Commons Public Domain Dedication waiver (http://creativecommons.org/publicdomain/zero/1.0/) applies to the data made available in this article, unless otherwise stated. 
(Continued from previous page)

Conclusion: This instrument makes a significant contribution to the identification of patients with palliative care needs as it has been designed to differentiate between general and specialised palliative care needs. Moreover, diagnostic data is not fundamental to the use of the instrument, thus facilitating its use by healthcare professionals other than physicians, in particular nurses. Internal and criterion validity assessments are ongoing and essential before wider dissemination of the instrument.

Keywords: Palliative care, Identification, Screening, Instrument, Item generation, Content validity, Interprofessional

\section{Background}

Palliative care has been clearly defined [1], but identifying individuals with palliative care needs is an ongoing challenge. In addition, the definition proposed by the World Health Organisation does not shed light on the distinction between needs for general and specialised PC. This distinction is, nevertheless, crucial to better understand the level of need in the population and thus improve access to appropriate PC and provide appropriate care [2-4]. Indeed, despite the development of PC, access to such care remains inequitable due to access to both specialists and generalists. This is particularly true for non-oncological patients and vulnerable populations [5]. Improved differentiation between patients requiring general and specialised PC will help the healthcare system to (i) better cope with the increase of PC needs related to demographic evolution, (ii) identify and meet the training needs of non-specialised PC professionals, and (iii) allow more efficient health spending through more equitable resource allocation and distribution [4-7]. As significant increases in PC needs are predicted, PC patient identification is an increasingly important public health concern. There is a consensus amongst experts in the field that PC should be initiated as early as possible in a patient's disease trajectory, in order to provide best patient and relative centred care [8], for which effective needs identification is essential.

Proportions of patients with PC needs vary (9$73 \%)$, and people are often identified late in their disease trajectory, which bears important consequences for care [9-18]. These consequences include, but are not limited to (i) excess hospital mortality, whereby $80 \%$ of palliative patients die in hospital when the majority of people wish to die at home [19, 20]; (ii) suboptimal symptom management [21-23]; (iii) unplanned hospitalisations with long hospital stays [24, 25]; (iv) prescription of inappropriate treatments due to a lack of advance care planning [26, 27]; and, (v) insufficient support for the patient and their relatives $[24,28,29]$. On the other hand, when patients receive PC, their health and wellbeing is enhanced through improved pain relief, less dyspnea and depression, and enhanced quality of life, patient satisfaction and chances of dying at home [30-35]. Furthermore, psychological distress, decisional conflict, acute interventions or hospital readmissions are reduced [36-39], and quality of life for families is improved [40].

Existing instruments to facilitate early identification of patients in need of PC have significant limitations: (i) none of the existing instruments differentiate between patients in need of general versus specialised PC; (ii) most of the existing instruments have undergone limited psychometric testing; and (iii) available identification instruments require medical diagnostic criteria and have been primarily designed for use by physicians, therefore excluding other key healthcare professionals [41]. Interprofessional perspectives in $\mathrm{PC}$ are essential in order to provide holistic care for both patients and relatives throughout the disease trajectory until death. It is therefore crucial that professionals other than physicians are also involved from the beginning of the trajectory, especially at the identification stage. In addition, nurses generally have the closest contact with patients and relatives which facilitates the assessment of their needs. Indeed, in daily clinical practice, nurses often identify PC needs and try to relay them to physicians. A new instrument should help nurses to systematize their evaluation and provide them with the necessary tools for accurately reporting these needs to interprofessional teams.

\section{Methods \\ Study design}

The aim of this study is to describe the development of a new PC screening instrument to identify patients in need of general and specialised palliative care independently of their disease.

The development of this instrument was based on DeVellis et al. [42] and Streiner et al.'s [43] recommendations for scale development. The instrument was developed through the following four steps: [1] determine the concept to measure [2]; generate a set of items [3]; review the item set by experts (content validity) [4]; administer items to a sample of the target population (face validity).

The intended application of the instrument is to assist all healthcare professionals in evaluating patients' palliative 
care needs. The target users of the instrument are mainly nurses and physicians, but potentially other healthcare professionals like social workers or physiotherapists. This instrument was designed for professionals, who do not necessarily have specific palliative care training, working in any acute care settings, except in intensive care units and emergency departments.

\section{Step 1: determine the concept to measure}

A literature review was conducted to identify existing definitions of general and specialised palliative care to inform item generation. The Pubmed, CINHAL, Embase, Cochrane, JBI databases, Google Scholar, government and hospice websites were consulted between January and March 2016. Published studies and national/international recommendations were used to answer the research question: what are the currently available definitions for general PC and for specialised PC? All articles identified were collated and uploaded into EndNote X8/2016 (Clarivate Analytics, PA, USA). Titles and abstracts were then screened in order to keep only full texts related to the topic of interest. Definitions were extracted from the selected full text articles and collated in an Excel file for comparison.

\section{Step 2: generate a set of items}

The aim of the second step was to obtain a list of possible items to include in the instrument. These items had to be relevant to the construct and the target population of interest, as well as for the context in which the instrument is intended to be used. This instrument is designed to be a clinician-reported outcome measure. As a result, the target population are non-specialised healthcare professionals and not patients. As the target population has some difficulties identifying patients requiring PC because professionals do not know the PC criteria, it was not deemed appropriate to include them at this stage of development.

For an instrument to meet the needs of busy healthcare professionals, it needs to be as concise and practical as possible. Regardless of whether the items referred to generalised or specialised PC, the first author (FTL) selected the relevant items from the literature, including published identification instruments [44-48]. This process was completed by a committee of interdisciplinary clinical experts in PC (CICE) including one clinical nurse specialist (FTL), one psychologist (MB1) and two physicians (MB2, GDB). This CICE was in charge of ensuring the relevance, comprehensiveness and comprehensibility for clinical practice, by analysing the data and the answers to the open questions, as well as by reformulating, adding or clustering items through discussions and deliberations [43]. An interprofessional working group was central in order to ensure that the different dimensions of PC are taken into account. The composition of the group was thought to be representative of the three professions most commonly involved in $\mathrm{PC}$ in Switzerland.

Following literature findings that people with life limiting non-oncological conditions have less access to palliative care $[16,23]$, the items were designed for patients with either oncological or non-oncological pathologies. Finally, the CICE determined which items belonged in the generalised PC or specialised PC categorisations.

\section{Step 3: review of initial set of items by experts}

A modified Delphi technique involving questionnaires with open and closed-ended questions was used to assess the relevance and the comprehensiveness of items related to general versus specialised PC from the final list generated in Step 2. These questionnaires were specifically developed for this participative process. Word documents were used to allow participants to report the items they chose for the instrument or to validate the final choices that were made. This occurred in the three rounds which allowed the content validity of the instrument to be established. The content validity can be enhanced during the development of an instrument through inclusion of experts of the discipline [49]. This method resulted in physicians and nurses from two linguistic regions of Switzerland (French and Italian), all experts in PC, to participating in the study [50-54]. A list of all nurses and physicians working in the different community-based specialist palliative care teams and all executive nurses and physicians of the PC units was compiled. Each of these professionals was contacted by email. This expert panel of clinicians specialised in PC was formed according to the following criteria: (i) a minimum of 3 years experience in PC, (ii) working in a hospice or in a hospital/community PC team, (iii) working in the French or Italian speaking regions of Switzerland, and (iv) having a sufficient oral and written level of French (as this part of the research was conducted in French). In addition, nurses were required to have undertaken specialised PC training or be a clinical nurse specialist or a head nurse. Physicians were required to be at least senior residents. Reasons for nonparticipation were not asked. Three rounds were necessary to achieve consensus (Fig. 1). In each round, a questionnaire including a list of items to be ranked according to the level of importance and one or two open questions for comments was sent to participants (all questionnaires are provided in Additional files 1, 2, 3). We carried out a pre-test with two nurses and one physician specialised in PC to assess the time necessary to complete questionnaires and the clarity of instructions.

In round 1, the participants ranked five items in order of priority for each set (general and specialised PC), with scores ranging from 5 (the most important) to 1 (the 


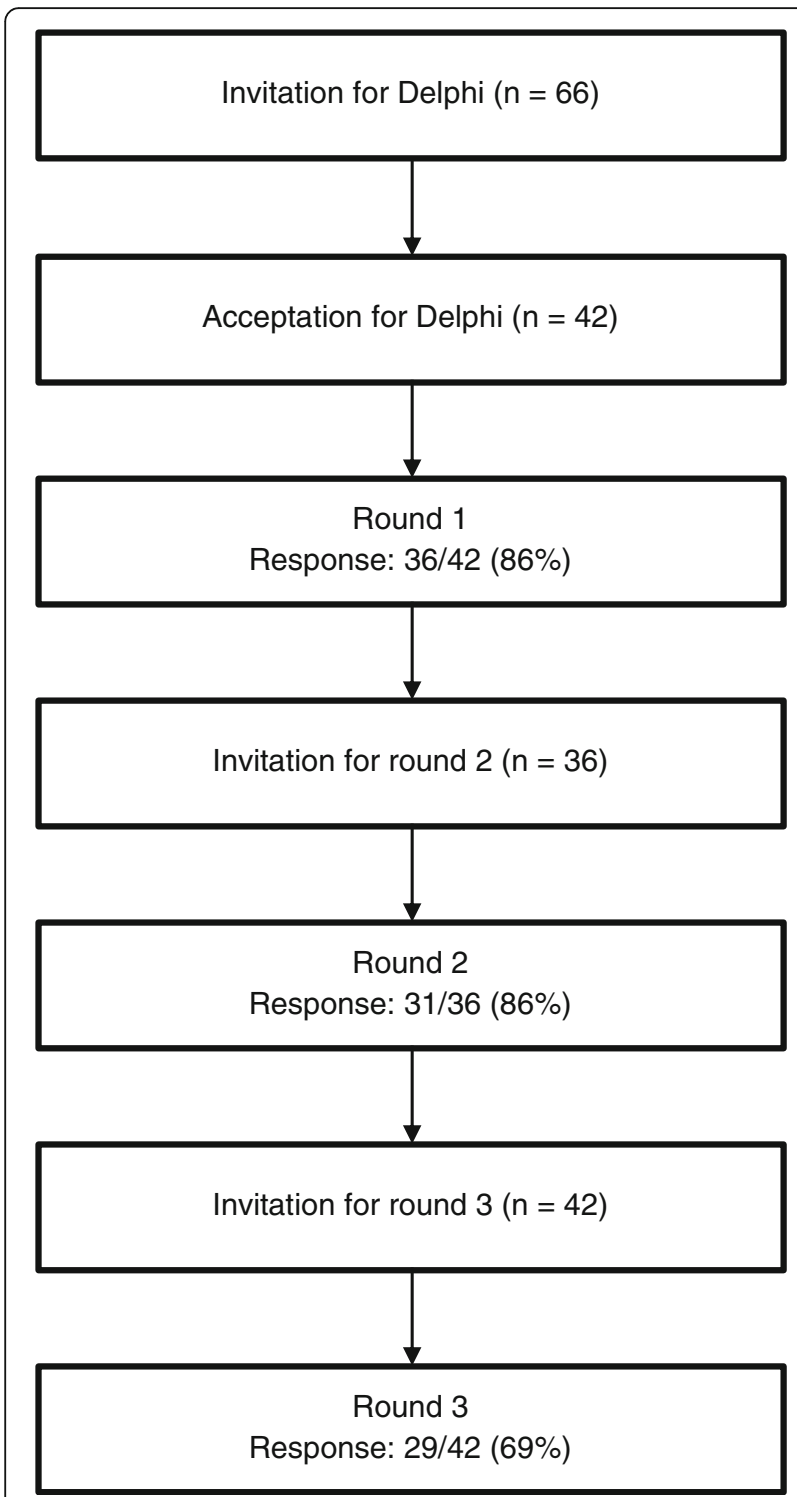

Fig. 1 Delphi process flowchart with specialist palliative care healthcare professionals

least important). The CICE recommended keeping items with a mean of $\geq 3.5$ and selected by more than half of the participants. Each comment was reviewed for its pertinence by the CICE and through consensus was reworded when judged appropriate. Thus, the choice of items was influenced by the overall consistency of the item selection and by the pertinence of the comments. If an item pertaining to a specific issue was chosen in the first round, other items related to this issue were excluded from the second round. The same was true for items that had not been chosen at all in the first round.

In round 2, the same participants were asked to choose the items they believed should be retained for the instrument from the list of items remaining from the first round. As none of the items were chosen by more than half of the participants and reached a mean of $\geq 3.5$, the CICE decided that only one of these two conditions had to be met.

In round 3, the aim was to confirm the item classification into either general or specialised PC and to ensure that the formulation was clear and understandable. A larger sample of experts, which also included those who participated in Round 1 and 2, were asked four yes/no questions to confirm (i) the relevance of the item selection in order to identify general and specialised PC patients, (ii) the comprehensibility and the clarity of the items and finally (iii) the name of the instrument. Two final sets of items (generalised PC and specialised PC) were developed at the end of the third round.

\section{Step 4: administer items to a sample of the target population for face validity}

The aim of this last step was to ensure the face validity of the final set of items with the target population of end-users, namely nurses and physicians, without specialised PC training and working in acute care settings at a Swiss university hospital. Inclusion criteria were: i) being a clinical nurse specialist or a senior resident physician; ii) working in internal medicine, surgery, oncology, cardiology, pulmonology or ambulatory setting; iii) having worked full time for at least 3 years in one of these units (or the part time equivalent of 3 years full time). An invitation to participate was sent to all the clinical nurse specialists of the hospital, as well as to senior residents collaborating with the hospital's mobile PC team. We sent participants a questionnaire including seven yes/no questions, pertaining to relevance, comprehensibility and feasibility. Space for extended responses for clarification or suggestions for "no" answers and other general comments were included in the questionnaire.

Descriptive analyses were conducted using IBM SPSS statistics 25. Classification of the comments was made by the first author (FTL) and then presented to the CICE for discussion.

\section{Results}

\section{Step 1: determine the concept to measure}

The origin of the construct of palliative care was grounded in the WHO definition (see above). The identification of patients requiring PC involves the ability to recognise them at the right time of their illness trajectory - depending on the patients' and relatives' needs in order to introduce a general approach to PC at the right time and to be aware of the appropriate time to refer to a specialised PC team $[2,3,16,55]$. General PC concerns all patients who have a life-threatening disease or who are at the end of life without complex biopsycho-socio-spiritual issues. These patients may be 
cared for by healthcare professionals with basic knowledge of PC $[55,56]$. General PC includes breaking bad news, relief of pain and other symptoms, establishing goals of care, and supporting patients and relatives throughout the continuum of care [6, 47, 57]. General PC may concern up to $80 \%$ of the proportion of patients requiring PC [2]. Specialised PC is for patients whose clinical situations are complex and/or unstable, and associated with high level of suffering of the patients and/ or their relatives $[55,56,58]$. Specialised PC and treatments should be provided by an interprofessional team, including physicians, nurses, psychologists, social workers, and spiritual assistants, who are specifically trained in PC $[47,57]$.

\section{Step 2: generate of a set of items}

The first author (FTL) selected 41 items from the literature (Table 1), including 21 items from the three most commonly used instruments: the Gold Standard Framework (GSF) [44], the Supportive and Palliative Care Indicator Tool (SPICT) [45], and the Necesidades Paliativas (NECPAL) [59] and 17 from other instruments or expert recommendations. Three different surprise questions with various expected times of death: 12 months, 6 months or "during the next months, weeks and days" were also integrated [60,61]. Items representative of physical decline (e.g. decreased ability to perform selfcare or less mobility) were retained. To ensure usability for key healthcare professionals other than physicians, items related to medical indicators of specific pathologies (e.g. cancer stages or spirometric criteria) were not included. Out of these 41 items, 32 were considered most relevant and understandable by the CICE. The CICE completed this first set of 32 items with 11 items derived from their clinical expertise. Clear, short items were written with dichotomous "yes" or "no" response categories because it is difficult for professionals to give a reliable estimation of the degree of difficulties encountered by the patients [43].

\section{Step 3: review of initial set of items by experts}

At least one physician and/or nurse of each of the specialised palliative care units and hospital or community PC team from each of the two linguistic regions were identified. A total of 71 professionals were screened for inclusion in the study; 66 met all inclusion criteria and 42 consented to participate. In the first round 19 nurses and 17 physicians participated; in the second 18 and 13; and in the third 15 and 14, respectively. Most of the participants had a specific training in PC (78\%), with an average of 13 years of $\mathrm{PC}$ clinical practice experience.

\section{Round 1}

For the general PC part, out of the 25 items, three items reached a mean of more than 3.5: (i) the 12-month surprise question $(\mathrm{M}=4.2(\mathrm{SD}=1.4) ; n=28)$, (ii) having life-limiting disease $(\mathrm{M}=4.0(\mathrm{SD}=1.3) ; n=29)$ and (iii) the patient or family member is seeking palliative care $(\mathrm{M}=3.5(\mathrm{SD}=1.3) ; n=25)$. For the specialised PC part, out of the 18 items, two items were selected: (i) persistence of uncontrolled symptoms $(\mathrm{M}=4.4(\mathrm{SD}=0.6) ; n=$ 27) and (ii) difficulty in assessing symptoms ( $\mathrm{M}=3.8$ $(\mathrm{SD}=0.9) ; n=18)$ (Table 2). In addition and following the comments' review by the CICE, three additional items were added to the Round 2 list, providing of a list of 25 items. Items with a mean $\leq 2$ and chosen by less than five experts were not included in round 2.

Table 1 Item generation process

\begin{tabular}{|c|c|c|}
\hline Development steps & Item selection & Results \\
\hline \multirow[t]{3}{*}{ Step 2: generate a set of items } & Initial set 1 of items (first author) & $\begin{array}{l}41 \text { items: } \\
21 \text { from GSF, SPICT and NECPALC } \\
17 \text { from other instruments and expert recommendations } \\
3 \text { different 'surprise' questions }\end{array}$ \\
\hline & Initial set 2 of items (CICE) & $\begin{array}{l}\mathbf{4 3} \text { items: } \\
32 \text { items selected from the initial set } \\
11 \text { new items added from the CICE clinical experience }\end{array}$ \\
\hline & Categorisation of second set of items (CICE) & $\begin{array}{l}\text { Two part instrument: } \\
25 \text { items for general PC } \\
18 \text { items for specialised PC }\end{array}$ \\
\hline \multirow[t]{3}{*}{ Step 3: review of initial set of items } & Delphi round 1 (expert panel) & $\begin{array}{l}\mathbf{5} \text { items: } \\
3 \text { items for general PC } \\
2 \text { items for specialised PC }\end{array}$ \\
\hline & Delphi round 2 (expert panel) & $\begin{array}{l}13 \text { items: } \\
7 \text { items for general PC } \\
6 \text { items for specialised PC }\end{array}$ \\
\hline & Delphi round 3 (expert panel) & $\begin{array}{l}\text { Two lists of items } \\
7 \text { items for general PC } \\
8 \text { items for specialised PC }\end{array}$ \\
\hline
\end{tabular}


Table 2 Item selection

\begin{tabular}{|c|c|c|}
\hline Items & Round $1 \mathrm{M} \pm \mathrm{SD} ; \mathrm{N}=36$ & Round $2 \mathrm{M} \pm \mathrm{SD} ; \mathrm{N}=31$ \\
\hline \multicolumn{3}{|l|}{ General PC } \\
\hline Surprise question 12 months & $4.1 \pm 1.4 ; n=20$ & \\
\hline Surprise question 6 months & $5.0 \pm 0.0 ; n=3$ & \\
\hline Surprise question months, weeks or days & $4.2 \pm 0.8 ; n=5$ & \\
\hline $\mathrm{PC}$ required by healthcare professional & $3.2 \pm 1.8 ; n=6$ & $4.3 \pm 1.0 ; n=7$ \\
\hline PC required implicitly or explicitly by patients or relatives & $3.5 \pm 1.3 ; n=19$ & \\
\hline PC required by patients/relatives & $3.3 \pm 1.4 ; n=6$ & \\
\hline Advanced illness, unstable symptoms & $3.8 \pm 1.6 ; n=5$ & \\
\hline Advanced illness and/or diminishing response to aetiological treatments & $4.3 \pm 0.5 ; n=8$ & \\
\hline Disease that cannot be treated, vital prognosis is underway & $4.0 \pm 1.3 ; n=16$ & \\
\hline Decreased response to treatment & $1.7 \pm 0.6 ; n=3$ & \\
\hline At least one disturbing symptom & $2.6 \pm 0.9 ; n=11$ & $4.1 \pm 0.8 ; n=11$ \\
\hline Decrease in general condition & $3.2 \pm 1.3 ; n=6$ & $4.8 \pm 0.5 ; n=4$ \\
\hline Poor or deteriorating performance status & $2.6 \pm 0.8 ; n=7$ & $3.8 \pm 0.8 ; n=9$ \\
\hline General functional decline & $1.9 \pm 0.8 ; n=8$ & $5.0 \pm 0.0 ; n=8$ \\
\hline Functional markers of decline & $2.5 \pm 0.6 ; n=4$ & \\
\hline Dependency on others for most care needs & $n=0$ & \\
\hline Nutritional markers of decline & $1.8 \pm 0.7 ; n=8$ & $4.0 \pm 0.6 ; n=4$ \\
\hline Significant weight loss & $2.0 \pm 0.8 ; n=4$ & \\
\hline Interruption of any vital support measures & $2.7 \pm 0.8 ; n=6$ & $4.0 \pm 0.8 ; n=11$ \\
\hline Other markers of severity and extreme fragility & $2.0 \pm 1.0 ; n=12$ & $3.7 \pm 0.7 ; n=9$ \\
\hline Sentinel events & $n=0$ & \\
\hline$\geq 2$ unscheduled hospitalizations & $1.8 \pm 1.0 ; n=9$ & $3.9 \pm 0.8 ; n=9$ \\
\hline$\geq 2$ concomitant diseases & $n=0$ & \\
\hline Significant co-morbidity & $2.0 \pm 1.1 ; n=7$ & $3.7 \pm 0.9 ; n=9$ \\
\hline Emotional distress & $1.8 \pm 0.7 ; n=8$ & $3.7 \pm 0.8 ; n=6$ \\
\hline \multicolumn{3}{|l|}{ Specialised $P C$} \\
\hline Specific population & $4.1 \pm 1.1 ; n=11$ & $3.6 \pm 1.6 ; n=8$ \\
\hline Rapidly evolving illness & $3.2 \pm 1.8 ; n=5$ & $3.8 \pm 1.7 ; n=8$ \\
\hline Need for complex and intense continuing care & $3.0 \pm 1.5 ; n=12$ & $2.3 \pm 1.0 ; n=9$ \\
\hline Persistent and distressing symptoms & $4.4 \pm 0.6 ; n=27$ & \\
\hline$\geq 3$ symptoms $>5$ on ESAS & $3.8 \pm 1.5 ; n=8$ & $3.6 \pm 1.5 ; n=10$ \\
\hline Uncontrolled pain & $3.2 \pm 1.2 ; n=9$ & $4.3 \pm 0.9 ; n=16$ \\
\hline Difficulties in assessing symptoms & $3.8 \pm 0.9 ; n=18$ & $3.5 \pm 1.1 ; n=15$ \\
\hline Severe psychological and/or existential distress & $2.6 \pm 1.0 ; n=18$ & $2.6 \pm 1.2 ; n=17$ \\
\hline Request for assisted suicide or euthanasia & $1.4 \pm 1.1 ; n=8$ & $2.2 \pm 1.5 ; n=6$ \\
\hline Psychosocial distress patient and/or relatives & $2.5 \pm 0.9 ; n=17$ & $3.0 \pm 1.1 ; n=11$ \\
\hline Difficulties in integrating information about the disease and/or prognosis & $1.0 \pm 0.0 ; n=1$ & \\
\hline Lack or insufficient support from relatives & $2.0 \pm 1.0 ; n=3$ & \\
\hline Social vulnerability & $2.0 \pm 0.0 ; n=1$ & \\
\hline Accompanying the patient is difficult & $1.4 \pm 0.8 ; n=7$ & \\
\hline Difficulties in communicating about therapeutic/care objectives & $1.8 \pm 0.4 ; n=6$ & $2.0 \pm 1.4 ; n=8$ \\
\hline Significant disagreement, uncertainty or conflict & $2.5 \pm 1.5 ; n=21$ & $2.8 \pm 1.4 ; n=22$ \\
\hline Need for support and/or second opinion for current decision-making & $1.9 \pm 0.8 ; n=9$ & \\
\hline
\end{tabular}


Table $\mathbf{2}$ Item selection (Continued)

\begin{tabular}{lll}
\hline Items & Round $1 \mathrm{M} \pm \mathrm{SD} ; N=36$ & Round $2 \mathrm{M} \pm \mathrm{SD} ; N=31$ \\
\hline Difficulties in writing advanced directives & $\mathrm{n}=0$ & $3.6 \pm 1.3 ; \mathrm{n}=5$ \\
Specialised PC team required by healthcare professional & $2.6 \pm 1.3 ; n=14$ \\
Palliative sedation envisaged & $1.3 \pm 0.6 ; n=3$ \\
Need for respite for the relatives & \\
\hline
\end{tabular}

\section{Round 2}

Considering the general PC part, seven items with a mean score of $\geq 3.7$ were selected. In order to minimise the number of items, the items related to the notion of vulnerability/frailty were grouped to obtain four items. Regarding the specialised PC part, two items obtained means $\geq 3.5$ and were chosen by more than half of the participants. Four others obtained either means $\geq 3.5$ or were selected by more than half of the participants. These six items were kept for the specialised PC part (Tables 2 and 3).

\section{Round 3}

$69 \%$ of participants $(n=20)$ thought that the general PC items would help healthcare professionals nonspecialised in PC to identify patients in need of general

Table 3 items kept for the instrument at each round

\begin{tabular}{ll}
\hline Items kept after first round & Items kept after second round \\
\hline General PC & \\
Surprise question 12 months & PC required by healthcare professional \\
PC required implicitly or explicitly & At least one distressing symptom \\
by patients or relatives & \\
$\begin{array}{ll}\text { Disease that cannot be treated, } \\
\text { vital prognosis is underway }\end{array}$ & General functional decline \\
& $\begin{array}{l}\text { Interruption of any vital support } \\
\end{array}$ \\
& measures \\
& Other markers of severity and \\
& extreme fragility \\
& $\geq 2$ unscheduled hospitalizations \\
& Significant co-morbidity \\
& Emotional distress
\end{tabular}

Specialised PC

Persistent and distressing symptoms Difficulties in assessing symptoms

Severe psychological and/or existential distress

Psychosocial distress patient and/or relatives

Difficulties in communicating about therapeutic/care objectives

Significant disagreement, uncertainty or conflict

Specialised $P C$ team required by healthcare professional

Palliative sedation envisaged
PC, and 76\% $(n=22)$ estimated that the specialised PC items would facilitate the identification of patients in need of specialised PC. Half of the participants suggested modifying some items for better understanding (e.g: to replace the term 'caregiver' by 'professional'; to give examples of what are considered life-sustaining measures; to replace 'life-threatening disease' by 'disease that limits life expectancy'). These suggestions were taken into account in the final set of items. Finally, the proposed name ID-PALLC for IDentification of the patient in need of PALLiative care was approved by $76 \%(n=22)$ of the participants; no other names were suggested.

Following the review of the written comments, some items were reworded. The goal of developing a short, consistent and user-friendly clinical instrument justified this process. Due to their different disciplines and backgrounds, the CICE members did not always immediately agree; intensive discussions were sometimes necessary to reach consensus. Reflection about the goal of developing a short, consistent and practical clinical instrument was helpful to finally reach consensus.

\section{Step 4: administer items to a sample of the target population for face validity}

Twenty nurses and eight physicians out of a total of 24 invited nurses and 24 invited physicians working in acute care setting at a Swiss university hospital participated in the face validation (57\%). Twenty-three participants $(82 \%)$ considered that the items would help them to identify patients in need of general PC and 24 (86\%) those in need of specialised PC. Twenty-seven professionals (96\%) thought that classification of items into general and specialised PC is needed to appropriately care for these patients. Twenty-two found the length and the presentation of the instrument appropriate and understood how to use it and how to interpret the results. On the other hand, 15 (54\%) asked for the clarity of some items to be improved. The main requests were to have fewer and shorter items; to clarify some items from the general part that were considered not specific enough; to arrange some items differently; to modify some terminology considered too vague (e.g 'uncomfortable symptoms') and to highlight keywords in each item. Following these suggestions, the wording of the relevant items were modified. Finally, two lists of items were obtained: one including seven items to identify patients in 
need of general PC and the other including eight items to identify specialised PC needs. A yes/no response categories are provided for each item. If one item is positive for the first part, the patient can be considered as in need of general PC. Evidence based recommendations for practice are then proposed and professionals are invited to complete the second part of the instrument. If two items are positive, the patient can be considered as in need of specialised PC. We recommend that each patient hospitalized for 24 to $48 \mathrm{~h}$ should be screened with ID-PALL@.

\section{Discussion}

To the best of our knowledge, this is the first study that aims to develop and validate a screening instrument to identify patients in need of general or specialised PC independently of disease type. From the literature, this distinction is crucial in order to identify the most suitable moment for implementing adequate PC $[3,16,55]$. A rigorous process for instrument development was followed to obtain items that could identify patients in need of generalised or specialised PC. Both the content and face validity process of the instrument were deemed to be acceptable within both the expert and the target populations. The name ID-PALL@ was chosen for the instrument that will be created based on these two lists of items.

Concerning the content validity, the qualitative feedback from the experts was pertinent and these comments allowed consensus to be achieved about the reformulation of certain items. However, in some instances, it was unclear as to how some comments could be used to modify the items because each participant contributed individually without a global vision of the instrument development that only the CICE had. The CICE's work was therefore crucial, requiring intensive discussions and adjustments in order to maintain global coherence with all the responses and to reach consensus on two lists of relevant items that cover the bio-psychosocial and spiritual dimensions of PC and which include the most important challenges facing health professionals. The interprofessionality of the group was a key element for these discussions. To maximise the utilisation of an innovation, such as a new instrument, several factors are important: (i) perceived benefits, (ii) compatibility with users' values, (iii) ease of use, (iv) experiment before implementation and (v) quick visibility of benefits [62]. Considering that time constraints are also a significant barrier to the adoption of innovative practice [62], ID-PALL@ was conceived to be brief and containing as few questions as necessary while still taking into account the key domains of PC and retaining content validity. This led the CICE to reduce the number of items early in the process, despite the fact that this is not generally recommended by experts [43]. Nevertheless, the results of the face validity phase showed that the instrument's brevity was much appreciated. As this screening instrument was designed to support healthcare professionals in their clinical reflection, brief evidence based recommendations will be added for initial guidance whenever general or specialised PC needs are identified by the instrument [63-65].

The referral rates for specialised PC remain low among health providers in all care settings, because of the difficulties in the timely identification of these patients $[16-18,35,40]$. This also means that it is difficult to know whether patients in need of general PC receive care that is adapted to their particular situation $[16,18$, 55]. Therefore, we carefully structured the two lists of items in such a way that it would be evident to professionals that patients with life limiting diseases should be evaluated for potentially unmet PC needs at an early stage, even if they don't meet the requirements for specialised PC. The main strength of the instrument is its two-part form, for general and specialised PC and its brevity and therefore quick utilisation. Additionally, due to its design and the fact that this instrument is not reliant on diagnosis data, this instrument has the potential to be used by healthcare professionals other than physicians, in particular by nurses as they have a more continuous presence and have a more holistic knowledge of the patients.

\section{Strengths and limitations}

Methodological strengths of this study include the diversity of the expert panel working in multiple PC settings, in different parts of Switzerland, with different practices, and also with varied PC backgrounds that reflect the diversity of the field. Another strength is the inclusion of the target population in the face validity process, thus reducing possible dissatisfaction of future users [43].

Imposing a limit on the number of items poses a potential limitation. However, experts and clinicians had the opportunity to add items, if they deemed it relevant, at all stages of the design. The Delphi process, based on the ranking of the five most important items, did not allow for the establishment of a Content Validity Index (CVI), which is recommended in the literature. We chose a local expert panel for maximum transferability in the subsequent validation study, and acknowledge that this may limit generalisation to other Frenchspeaking regions. In addition, while the CICE was an interprofessional working group, the absence of chaplains and social workers may limit its representativeness of the different dimensions of PC, particularly concerning spiritual and social aspects. With respect to the face validity, cognitive debriefing during the completion of the instrument may have provided valuable insights into the 
ways in which the instrument is completed and the different factors taken into account when responding. Cognitive debriefing has thus been planned as part of the subsequent implementation study. A further limitation of this study is the absence of service user input into the CICE. Service user input will feature prominently in the pilot implementation studies of the new validated instrument. Finally, the face validity was only conducted with hospital healthcare professionals, thus validation in different care settings should be conducted in the future.

\section{Conclusions}

These results represent the first step of the validation process of the newly developed ID-PALL( $\odot$ instrument. The methods used in the development have resulted in an instrument that is brief and tailored to the needs of all health professionals, nurses in particular, who are confronted with patients with a potential need for PC. This instrument should allow the distinction between patients requiring general vs. specialised PC, regardless of their pathology. We are currently analysing the criterion validity of this instrument in order to assess its sensitivity and the specificity compared with the evaluation of a specialised interprofessional PC team including both nurses and physicians. An implementation study is currently being designed for the wider implementation of this instrument into clinical practice.

\section{Supplementary information}

Supplementary information accompanies this paper at https://doi.org/10. 1186/s12904-020-0522-6

Additional file 1. Delphi questionnaire round 1. This questionnaire was send to the participants to choose the most relevant items for the instrument and the best formulation for each item. This questionnaire was originally in French. We present a literal translation in this article.

Additional file 2. Delphi questionnaire round 2. This questionnaire was send to the participants to choose the most relevant items for the instrument and the best formulation for each item. This questionnaire was originally in French. We present a literal translation in this article.

Additional file 3. Delphi questionnaire round 3. This questionnaire was send to the participants to assess the relevance and the comprehensibility of the final items, and also the name of the instrument. This questionnaire was originally in French. We present a literal translation in this article.

\section{Abbreviations \\ CICE: Committee of interdisciplinary clinical experts; CVI: Content validity index; GSF: Gold standard framework; ID-PALLO: IDentification of patients in need of general and specialised PALLiative care; M: Mean; \\ NECPAL: Necesidades paliativas; PC: Palliative care; SD: Standard deviation; SPICT: Supportive and palliative care indicator tool; WHO: World Health Organization}

\section{Acknowledgements}

The authors wish to thank Laura Jones for her attentive and professional proofreading and correction of the manuscript; all professionals who participated in the content and face validities; to C. Hoenger, I. Lehn, V. Champier, Prof JB Wasserfallen, Prof G. Waeber and S. Gallant of the project steering committee of the Lausanne University Hospital for their advice and linkage to the needs of target populations.

\section{Authors' contributions}

$F T L, M B 1, C G$ and GDB designed the study. FTL conducted the study. FTL and ASR conducted the appraisal of the identified instruments. FTL conducted the item generation, the Delphi process and the face validity. FTL analysed the data with the support of MB1. FTL, MB1, MB2 and GDB were part of the committee of interdisciplinary clinical experts; they supervised the item generation and the development of the instrument. All authors accepted the final manuscript. All authors read and approved the final manuscript.

\section{Funding}

The Swiss Academy for Medical Sciences funded this study through the "Research in palliative care" programme. The funds were used for hiring Author 1. The funding body was not involved in any part of the study design, data collection, analysis or interpretation, or in writing the manuscript. The first author is also supported for her PhD thesis by the Public health service of the Canton de Vaud and Ticino, the Palliative and supportive care service, the Training center and the Head of nursing of the Lausanne University Hospital.

\section{Availability of data and materials}

The datasets used and analysed during the current study are available from the corresponding author on request.

\section{Ethics approval and consent to participate}

When contacted for approval, and in accordance with the Swiss Ethics laws [66], the Ethical Committee informed us that as the participants in this study were not patients and this research did not involve the use of medical records of patients, this study did not need approval from the committee. However, this study was conducted in accordance with the general ethical principles for conducting research as stipulated in the Human Research Ordinance rules. Written consent of the participants were obtained.

Consent for publication

Not applicable.

\section{Competing interests}

The authors declare that they have no competing interests.

\section{Author details}

${ }^{1}$ Institute of Higher Education and Research in Healthcare, University of Lausanne and Lausanne University Hospital, Lausanne, Switzerland. ${ }^{2}$ Palliative and Supportive Care Service, Lausanne University Hospital and University of Lausanne, Lausanne, Switzerland. ${ }^{3}$ Palliative and Supportive Care Clinic,

Oncology Institute of Southern Switzerland, Bellinzona, Switzerland.

Received: 13 September 2019 Accepted: 5 February 2020

Published online: 12 February 2020

\section{References}

1. World Health Organization. WHO Definition of Palliative Care 2002. Available from: https://www.who.int/cancer/palliative/definition/en/.

2. von Wartburg L. Soins palliatifs généraux. Recommandations et instruments de mise en œuvre. Berne: Office fédéral de la santé publique OFSP,

Conférence suisse des directrices et directeurs cantonaux de la santé CDS \& Palliative ch; 2015.

3. Radbruch L, Payne S. Board of Directors of the European Association for Palliative Care. White Paper on standards and norms for hospice and palliative care in Europe: part 1 and 2. Eur J Palliat Care. 2009;16(6):278-89.

4. Etkind SN, Bone AE, Gomes B, Lovell N, Evans CJ, Higginson IJ, et al. How many people will need palliative care in 2040? Past trends, future projections and implications for services. BMC Med. 2017;15(1):102.

5. Dixon J, King D, Matosevic T, Clark M, Knapp M. Equity in the provision of palliative care in the UK: review of evidence. London: Personal Social Services Research Unit London School of Economics and Political Science; 2015 
6. Gamondi C, Larkin P, Payne S. Core competencies in palliative care: an EAPC white paper on palliative care education - part one. Eur J Palliat Care. 2013; 20(2):86-91.

7. Gomes B, Calanzani N, Curiale V, McCrone P, Higginson IJ. Effectiveness and cost-effectiveness of home palliative care services for adults with advanced illness and their caregivers. Cochrane Database Syst Rev. 2013;6:CD007760.

8. Lamba S. Early goal-directed palliative therapy in the emergency department: a step to move palliative care upstream. J Palliat Med. 2009; 12(9):767.

9. To TH, Greene AG, Agar MR, Currow DC. A point prevalence survey of hospital inpatients to define the proportion with palliation as the primary goal of care and the need for specialist palliative care. Intern Med J. 2011; 41(5):430-3.

10. van Niekerk L, Raubenheimer PJ. A point-prevalence survey of public hospital inpatients with palliative care needs in Cape Town, South Africa. South Africa Med J. 2014;104(2):138-41.

11. Gott M, Frey R, Raphael D, O'Callaghan A, Robinson J, Boyd M. Palliative care need and management in the acute hospital setting: A census of one New Zealand Hospital. BMC Palliat Care. 2013;12(1):1-8.

12. Murtagh F. Can palliative care teams relieve some of the pressure on acute services? BMJ. 2014;348:93693.

13. Morin L, Aubry R, Frova L, MacLeod R, Wilson DM, Loucka M, et al. Estimating the need for palliative care at the population level: a crossnational study in 12 countries. Palliat Med. 2017;31(6):1-11.

14. Zertuche-Maldonado T, Tellez-Villarreal R, Pascual A, Valdovinos-Chavez SB, Barragan-Berlanga AJ, Sanchez-Avila MT, et al. Palliative care needs in an acute internal medicine Ward in Mexico. J Palliat Med. 2018;21(2):163-8.

15. Meffert C, Rucker G, Hatami I, Becker G. Identification of hospital patients in need of palliative care--a predictive score. BMC Palliat Care. 2016;15:21.

16. Rosenwax L, Spilsbury K, McNamara BA, Semmens JB. A retrospective population based cohort study of access to specialist palliative care in the last year of life: who is still missing out a decade on? BMC Palliat Care. 2016; 15:46

17. Sarradon-Eck A, Besle S, Troian J, Capodano G, Mancini J. Understanding the barriers to introducing early palliative Care for Patients with advanced Cancer: a qualitative study. J Palliat Med. 2019;22(5):508-16.

18. Flierman I, Nugteren IC, van Seben R, Buurman BM, Willems DL. How do hospital-based nurses and physicians identify the palliative phase in their patients and what difficulties exist? A qualitative interview study. BMC Palliat Care. 2019;18(1):54

19. Office fédéral de la santé publique, Conférence suisse des directrices et directeurs cantonaux de la santé. Stratégie nationale en matière de soins palliatifs 2013-2015. Berne: OFSP et CDS; 2012.

20. Pollock K. Is home always the best and preferred place of death? BMJ. 2015; 351:h4855.

21. Murtagh FE, Addington-Hall J, Edmonds P, Donohoe P, Carey I, Jenkins K, et al. Symptoms in the month before death for stage 5 chronic kidney disease patients managed without dialysis. J Pain Symptom Manag. 2010; 40(3):342-52.

22. Manitta V, Zordan R, Cole-Sinclair M, Nandurkar H, Philip J. The symptom burden of patients with hematological malignancy: a cross-sectional observational study. J Pain Symptom Manag. 2011;42(3):432-42.

23. Penders YW, Onwuteaka-Philipsen B, Moreels S, Donker GA, Miccinesi G, Alonso TV, et al. Differences in primary palliative care between people with organ failure and people with cancer: an international mortality follow-back study using quality indicators. Palliat Med 2018;32(9):1498-508.

24. Rosenwax L, Spilsbury K, Arendts G, McNamara B, Semmens J. Communitybased palliative care is associated with reduced emergency department use by people with dementia in their last year of life: a retrospective cohort study. Palliat Med. 2015;29(8):727-36.

25. Seow H, Brazil K, Sussman J, Pereira J, Marshall D, Austin PC, et al. Impact of community based, specialist palliative care teams on hospitalisations and emergency department visits late in life and hospital deaths: a pooled analysis. BMJ. 2014;348:g3496.

26. Dalgaard KM, Bergenholtz H, Nielsen ME, Timm H. Early integration of palliative care in hospitals: a systematic review on methods, barriers, and outcome. Palliative Support Care. 2014;12(6):1-19.

27. Lindsay J, Dooley M, Martin J, Fay M, Kearney A, Barras M. Reducing potentially inappropriate medications in palliative cancer patients: evidence to support deprescribing approaches. Support Care Cancer. 2014;22(4): $1113-9$.
28. Greer JA, Jackson VA, Meier DE, Temel JS. Early integration of palliative care services with standard oncology care for patients with advanced cancer. CA Cancer J Clin. 2013;63(5):349-63.

29. Temel JS, Greer JA, El-Jawahri A, Pirl WF, Park ER, Jackson VA, et al. Effects of early integrated palliative Care in Patients with Lung and GI Cancer: a randomized clinical trial. J Clin Oncol. 2017:35(8):834-41.

30. Gomes B, Higginson IJ. Factors influencing death at home in terminally ill patients with cancer: systematic review. BMJ. 2006;332(7540):515-21.

31. Haun MW, Estel S, Rucker G, Friederich HC, Villalobos M, Thomas M, et al. Early palliative care for adults with advanced cancer. Cochrane Database Syst Rev. 2017;6:CD011129.

32. Kavalieratos D, Corbelli J, Zhang D, Dionne-Odom JN, Ernecoff NC, Hanmer J, et al. Association between palliative care and patient and caregiver outcomes: a systematic review and meta-analysis. JAMA. 2016;316(20):2104-14.

33. Mudumbi SK, Bourgeois CE, Hoppman NA, Smith CH, Verma M, Bakitas MA, et al. Palliative care and hospice interventions in decompensated cirrhosis and hepatocellular carcinoma: a rapid review of literature. J Palliat Med. 2018;21(8):1177-84.

34. Veronese S, Gallo G, Valle A, Cugno C, Chio A, Calvo A, et al. Specialist palliative care improves the quality of life in advanced neurodegenerative disorders: NE-PAL, a pilot randomised controlled study. BMJ Support Palliat Care. 2015;7(12):164-72.

35. Kassianos AP, Ioannou M, Koutsantoni M, Charalambous $H$. The impact of specialized palliative care on cancer patients' health-related quality of life: a systematic review and meta-analysis. Support Care Cancer. 2018;26(1):61-79.

36. Dionne-Odom JN, Azuero A, Lyons KD, Hull JG, Tosteson T, Li Z, et al. Benefits of early versus delayed palliative care to informal family caregivers of patients with advanced Cancer: outcomes from the ENABLE III randomized controlled trial. J Clin Oncol. 2015;33(13):1446-52.

37. De Palma R, Fortuna D, Hegarty SE, Louis DZ, Melotti RM, Moro ML. Effectiveness of palliative care services: a population-based study of end-oflife care for cancer patients. Palliat Med. 2018;32(8):1344-52.

38. Sutradhar R, Barbera L, Seow HY. Palliative homecare is associated with reduced high-and low-acuity emergency department visits at the end of life: a population-based cohort study of cancer decedents. Palliat Med. 2017 31(5):448-55.

39. Barkley JE, McCall A, Maslow AL, Skudlarska BA, Chen X. Timing of palliative care consultation and the impact on thirty-day readmissions and inpatient mortality. J Palliat Med. 2019;22(4):393-9.

40. Davis MP, Temel JS, Balboni T, Glare P. A review of the trials which examine early integration of outpatient and home palliative care for patients with serious illnesses. Ann Palliat Med. 2015;4(3):99-121.

41. Federal Office of Public Health (FOPH), Swiss Conference of the Cantonal Ministers of Public Health (CMH), palliative.ch. Framework Concept for Palliative Care in Switzerland: A basis for defining palliative care for the implementation of the «National Strategy for Palliative Care». Bern; 2014.

42. DeVellis R. Scale development: theory and applications. 3rd ed. California: SAGE Publications; 2012.

43. Streiner D, Norman G, Cairney J. Health measurement scales. 5th ed. New York: Oxford University Press; 2015.

44. Thomas K, Noble B. Improving the delivery of palliative care in general practice: an evaluation of the first phase of the gold standards framework. Palliat Med. 2007;21(1):49-53.

45. Highet G, Crawford D, Murray SA, Boyd K. Development and evaluation of the supportive and palliative care indicators tool (SPICT): a mixed-methods study. BMJ Support Palliat Care. 2014;4(3):285-90.

46. Gomez-Batiste X, Martinez-Munoz M, Blay C, Amblas J, Vila L, Costa X, et al. Identifying patients with chronic conditions in need of palliative care in the general population: development of the NECPAL tool and preliminary prevalence rates in Catalonia. BMJ Support Palliat Care. 2013;3(3):300-8.

47. Weissman DE, Meier DE. Identifying patients in need of a palliative care assessment in the hospital setting: a consensus report from the center to advance palliative care. J Palliat Med. 2011;14(1):17-23.

48. Thoonsen B, Engels $Y$, van Rijswijk E, Verhagen $S$, van Weel $C$, Groot $M$, et al. Early identification of palliative care patients in general practice: development of RADboud indicators for PAlliative care needs (RADPAC). Br J Gen Pract. 2012;62(602):e625-31.

49. Polit DF, Yang FM. Measurement and the measurement of change. Philadelphia: Wolters Kluwer; 2016.

50. Keeney S, Hasson F, McKenna HP. A critical review of the Delphi technique as a research methodology for nursing. Int J Nurs Stud. 2001;38(2):195-200. 
51. Biondo PD, Nekolaichuk CL, Stiles C, Fainsinger R, Hagen NA. Applying the Delphi process to palliative care tool development: lessons learned. Support Care Cancer. 2008;16(8):935-42.

52. Ramelet AS, Gill F, Group APICSI. A Delphi study on national PICU nursing research priorities in Australia and New Zealand. Aust Crit Care. 2012;25(1): 41-57.

53. van Vliet LM, Harding R, Bausewein C, Payne S, Higginson IJ. Euroimpact. How should we manage information needs, family anxiety, depression, and breathlessness for those affected by advanced disease: development of a Clinical Decision Support Tool using a Delphi design. BMC Med. 2015;13:263.

54. Maleki K. Méthodes quantitatives de consultation d'experts. Paris: Ed. Publibook; 2009 .

55. Afshar K, Geiger K, Muller-Mundt G, Bleidorn J, Schneider N. Generalist palliative care for non-cancer patients : a review article. Schmerz. 2016;29(6): 604-15.

56. Brown CR, Hsu AT, Kendall C, Marshall D, Pereira J, Prentice M, et al. How are physicians delivering palliative care? A population-based retrospective cohort study describing the mix of generalist and specialist palliative care models in the last year of life. Palliat Med. 2018;32(8):1334-43.

57. Andersen A, Tracy M, Nailon R, Gaster S, Mooberry R, Meza J. Examination of the interrater reliability of a palliative care assessment tool in patients at hospital admission. J Hosp Palliat Nurs. 2013:15(8):491-8.

58. Binder J, Von Wartburg L. Directives nationales concernant les soins palliatifs. Berne: Office fédéral de la santé publique OFSP \& Conférence suisse des directrices et directeurs cantonaux de la santé CDS; 2014.

59. Gómez-Batiste X, Martínez-Muñoz M, Blay C, Amblàs J, Vila L, Costa X Identification of people with chronic advanced diseases and need of palliative care in sociosanitary services: elaboration of the NECPAL CCOMSICO@ tool. Med Clin (Barc). 2013;140(6):241-5.

60. Downar J, Goldman R, Pinto R, Englesakis M, Adhikari NK. The "surprise question" for predicting death in seriously ill patients: a systematic review and meta-analysis. CMAJ. 2017;189(13):E484-E93.

61. Rice J, Hunter L, Hsu AT, Donskov M, Luciani T, Toal-Sullivan D, et al. Using the "surprise question" in nursing homes: a prospective mixed-methods study. J Palliat Care. 2017:33(1):9-18.

62. Rogers E. Diffusion of innovations. New York: The Free Press; 2003.

63. Bernacki RE, Block SD, American College of Physicians High Value Care Task F. Communication about serious illness care goals: a review and synthesis of best practices. JAMA Intern Med. 2014;174(12):1994-2003.

64. McCusker M, Ceronsky L, Crone C, Epstein H, Greene B, Halvorson J, et al. Palliative care for adults. Bloomington: Insitute for Clinical Systems Improvement; 2013

65. National Institute for Clinical Excellence. Improving supportive and palliative care for adults with cancer. London: National Institute for Clinical Excellence; 2004.

66. Loi relative à la recherche sur l'être humain (LRH), art 2 (2011).

\section{Publisher's Note}

Springer Nature remains neutral with regard to jurisdictional claims in published maps and institutional affiliations.

Ready to submit your research? Choose BMC and benefit from:

- fast, convenient online submission

- thorough peer review by experienced researchers in your field

- rapid publication on acceptance

- support for research data, including large and complex data types

- gold Open Access which fosters wider collaboration and increased citations

- maximum visibility for your research: over $100 \mathrm{M}$ website views per year

At BMC, research is always in progress.

Learn more biomedcentral.com/submissions 